\title{
Management of a Large Sublingual Dermoid Cyst
}

\author{
Le $\mathrm{V}^{1,2}$, Byrne $\mathrm{H}^{1,2^{*}}$, Kearns $\mathrm{GJ}^{1,2}$ and Ekanayake $\mathrm{K}^{1,2}$ \\ ${ }^{1}$ Oral and Maxillofacial Department, St. James Hospital, Ireland \\ ${ }^{2}$ Oral and Maxillofacial Department, Our Lady's Children's Hospital Crumlin, Ireland
}

\begin{abstract}
This case report highlights our management of a large sublingual dermoid cyst.

A fifteen-year-old Irish male presented with a swelling in the floor of mouth and displacement of the tongue. Speech changes were noted on presentation. A magnetic resonance imaging (MRI) scan revealed a $7 \times 4 \times 3 \mathrm{~cm}$ mass in the submental and sublingual spaces. Fine needle aspiration suggested a dermoid cyst. We excised the cyst via an intraoral approach. Sublingual dermoid cysts are rare entities, and their management has been poorly described. Our case report illustrates the value of an intraoral surgical approach.
\end{abstract}

\section{Introduction}

Dermoid cysts of the oral cavity most commonly occur in the midline floor of the mouth but can be displaced laterally or develop in other locations. Dermoid cysts are prevalent in the head and neck with a range of 1.6-6.9\% and are extremely rare in the oral cavity, representing less than $0.01 \%$ of all oral cavity cysts [1-5]. The cyst can develop above the geniohyoid/mylohyoid muscles causing a displacement of the tongue cranially toward the roof of the mouth and functional implications include eating, speaking, breathing and cosmesis. They may also develop below the geniohyoid/mylohyoid giving rise to a "double chin" appearance [1].

Oral sublingual dermoids can vary in size from a few $\mathrm{mm}$ to $12 \mathrm{~cm}$ in diameter. They are slow in growth, and they are most commonly diagnosed in the first to third decade. They may be either acquired (85\%) or congenital (15\%), both of which are histologically identical [1]. There has no definitive gender predisposition however the literature has noted a greater male predominance in some case series [1]. They are usually asymptomatic, indolent and develop slowly over time.

Sublingual and submental dermoids start in the midline and may extend laterally and downward and can attain a large size before presentation [6,7]. A sudden increase in size has been reported during the onset of puberty due to an increase production of sebum from the sebaceous glands [8]. They can displace the tongue, and patients may present with dysphagia, dysphonia, and dyspnea or when below the geniohyoid muscle, can produce a submental swelling or "double-chin" effect [9]. Alternatively, sudden expansion may be due to secondary infections with drainage intraorally or cervically $[6,10,11]$.

Dermoid cysts are squamous epithelial-lined cysts that contain dermal adnexal structures in the cyst wall. Dermoid cysts differ histologically from epidermoid cysts which lack skin appendages, and the latter may represent the simplest form on the teratoma spectrum. These are not to be confused with epidermoid cyst of the skin, a non-teratomatous lesion arising from the hair follicle.

Definitive management of dermoid cysts is total excision. Malignant transformation into squamous cell carcinoma is rare [12]. The true incidence of oral dermoids is not known due to the inclusion of epidermoid and teratomas in many publications $[10,13,14]$. Therefore, true sublingual dermoids are rare entities and the management is poorly described. Multiple surgical approaches have been described depending on the location of the cyst. Those located above the geniohyoid can be removed intraorally [15-18], while dermoid cysts occurring below the geniohyoid may require an extraoral approach [16-18]. We discuss the presentation and surgical management of a large sublingual dermoid via an intraoral approach.

\section{Case}

A 15-year-old Irish male presented with a sublingual swelling, located in the anterior floor of mouth. The swelling was increasing in size over the past four months. He complained

*Corresponding author: Harriet Byrne, Oral and Maxillofacial Senior House Officer, Oral and Maxillofacial Department, National Maxillofacial Unit, St. James Hospital, James Street, Dublin 8, D08NHY1, Ireland

Accepted: May 27, 2021

Published online: May 29, 2021

Citation: Le V, Byrne H, Kearns GJ, et al. (2021) Management of a Large Sublingual Dermoid Cyst. Arch of Pedia Surg 5(1):104108

Copyright: (C) 2021 Le V, et al. This is an open-access article distributed under the terms of the Creative Commons Attribution License, which permits unrestricted use, distribution, and reproduction in any medium, provided the original author and source are credited. 
of swallowing difficulties, voice change and restrictive tongue mobility. Extraoral examination revealed a firm, non-tender sublingual expansion located in the midline. The swelling was mobile, non-tender on bimanual palpation, well demarcated and had dough like consistency. No overlying mucosal or skin changes noted. There was displacement of Wharton's ducts lateral and caudally however salivary flow was satisfactory (Figure 1 and Figure 2).

\section{Cytology}

An aspiration of the mass revealed cloudy, straw-coloured

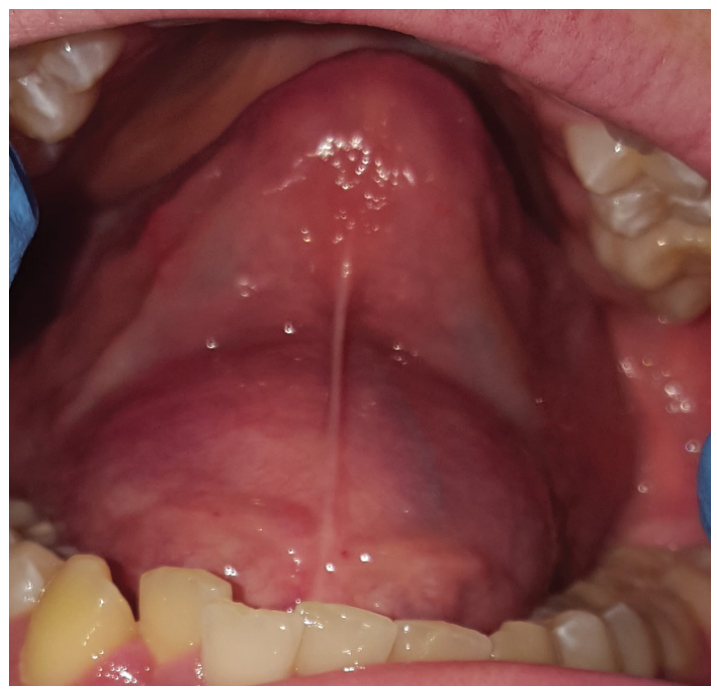

Figure 1: Highlights an intraoral view of the midline symmetrical sublingual swelling on the anterior floor of mouth. The swelling was soft, mobile with no evidence of mucosal changes. The swelling was symmetrical and was coincident with the centre line along the lingual frenum. intraluminal debris. This ruled out a salivary and vascular pathology. Cytological examination of this fluid demonstrated very occasional benign squamous epithelial cells together with proteinaceous material. These features were suggestive of a sublingual dermoid cyst. Therefore, it was elected to excise the sublingual mass.

\section{Surgical Procedure}

An intraoral excision was the treatment of choice. Under general anaesthetic nasal intubation, traction sutures were secured through the tip of the tongue and to allow access to the ventral aspect of the tongue and floor of mouth.

Initial cannulation of Wharton's duct with lacrimal probes facilitated identification and orientation of the ducts. Local anesthetic with epinephrine was injected submucosally around the mass to hydro dissect the mucosa and aid in haemostasis. An incision was made along the lingual fraenum. Care was taken not to interfere with the cyst lining and retraction of Wharton's ducts. Once the dissection plane between the cyst wall and mucosa was established, dissection along this avascular plane was completed.

This involved dissecting over the superior aspect of the cyst and elevating the genioglossus muscle fibers off the capsule. Laterally, the cyst travelled between the geniohyoid muscles, and lateral retraction of the geniohyoid muscles allows access to the submental space. The inferior surface was relieved with gentle digital pressure from the submental region. This brought the deeper plane to a more superficial level, enabling better visualization and dissection. The inferior cyst wall was dissected from the mylohyoid. Submental drains were inserted and secured after the excision (Figure 3, Figure 4 and Figure 5).

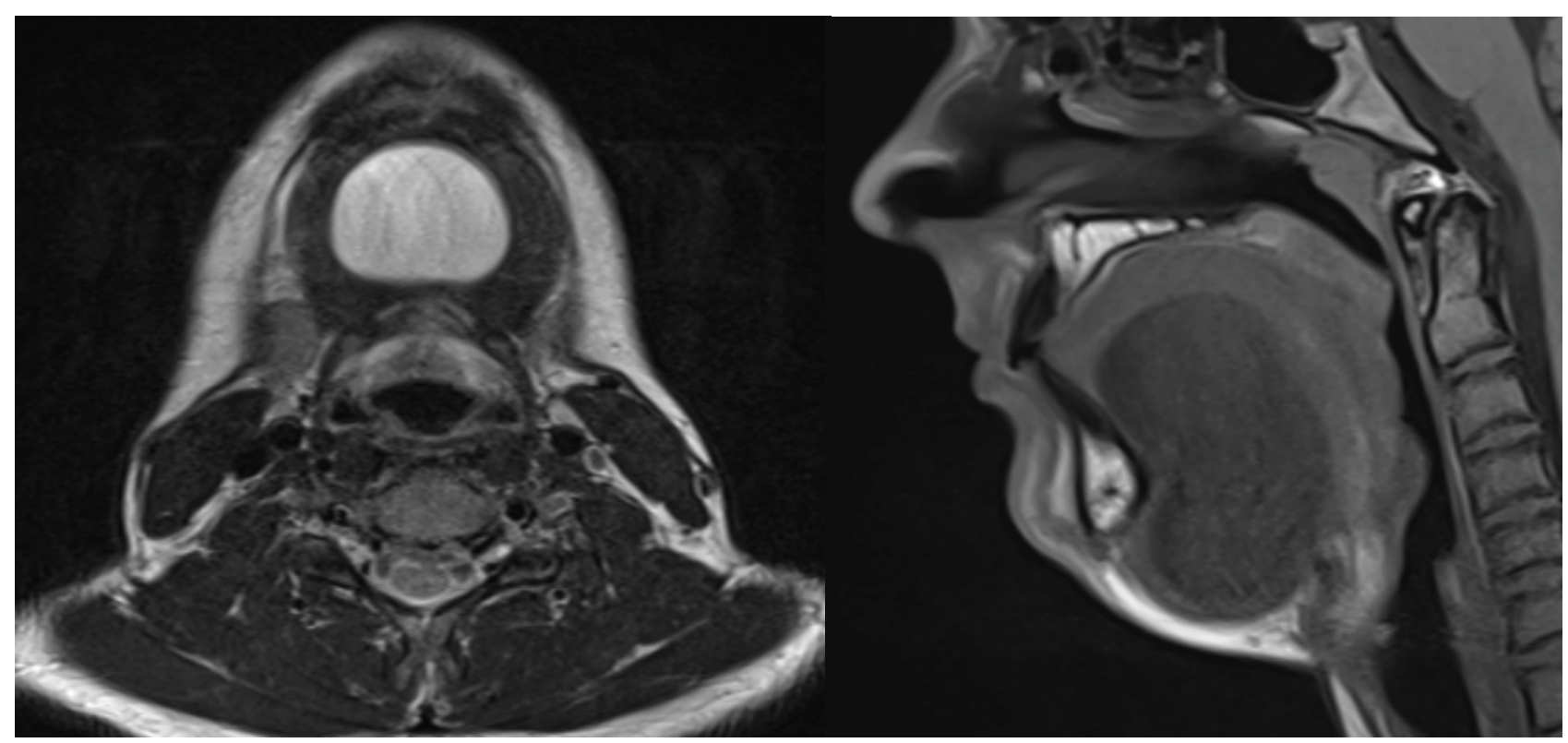

Figure 2: Highlights axial and sagittal from a magnetic resonance imaging (MRI) scan of a $7 \times 4 \times 3 \mathrm{~cm}$ mass in the floor of mouth. It is homogenous and had a high signal on T2 and a low signal of T1 MRI. The superior margin abuts the genioglossus, extends to the base of tongue posteriorly, between the geniohyoid muscles, to the level of the hyoid inferiorly. 


\section{Histopathology}

The specimen consisted of a $7.4 \mathrm{~cm} \times 4.2 \mathrm{~cm} \times 3.5 \mathrm{~cm}$ orthokeratinized squamous epithelial lined cyst with skin adnexal structures in the cyst wall consistent with a dermoid cyst. Haemorrhage, inflammatory infiltrate and multinucleated cells were noted, in keeping with the previous aspiration (Figure 6).

There were no postoperative complications. The drains were removed the following day and the patient was discharged on day 2 and the wound healed without complica-

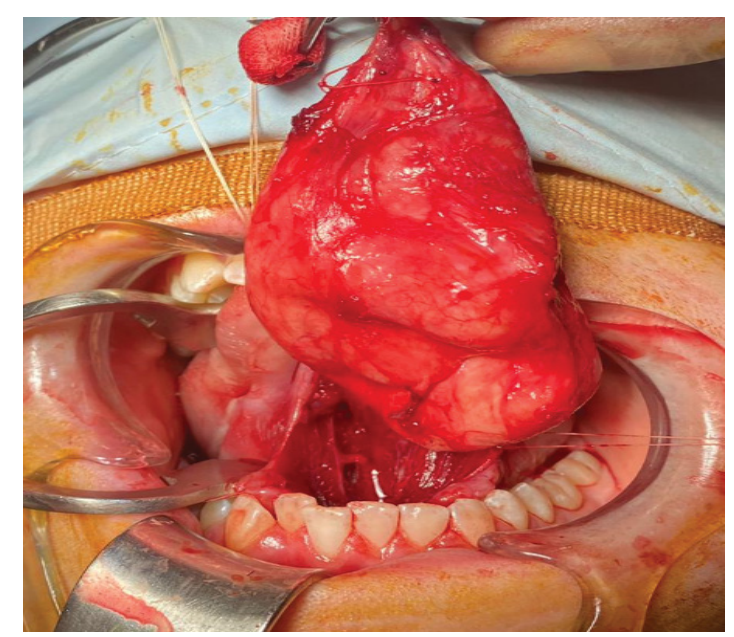

Figure 3: Is an intraoperative view of the intact cyst after careful dissection around the mass. Areas of adhesion to the surrounding muscles were apparent between the geniohyoid muscles and mylohyoid muscles during the excision. tion. There were no changes in speech, neurosensory deficits, salivary pathology or functional problems were observed at the 6-month follow up. No recurrence was observed.

\section{Discussion}

Sublingual dermoid cysts are rare, benign cysts. Dermoid cysts are most commonly found in the ovaries and testacies. $7 \%$ of dermoid cysts occur in the head and neck, while $1.6 \%$ occurs in the mouth [15]. There is no significant gender predilection however a review of literature by Vélez-Crus, et al. noted a high incidence among men after 30 years (84.61\%) and only $15.38 \%$ among women [19]. A higher male predominance $(3: 1)$ was also noted by Longo, et al. in his review of 16 dermoid cyst cases [20].

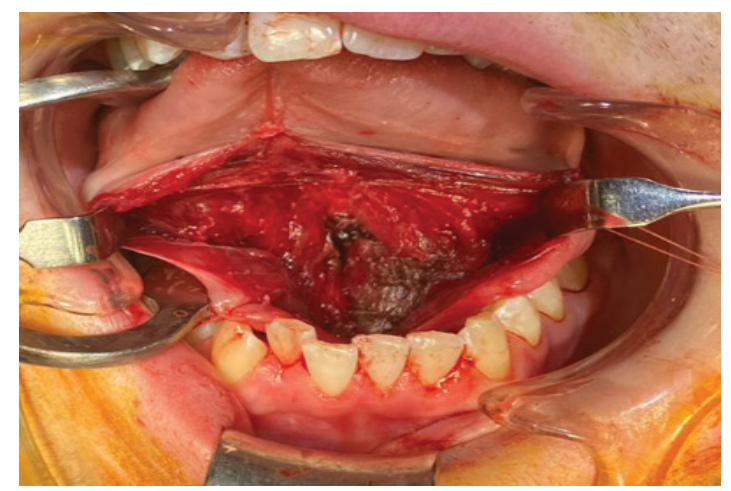

Figure 4: Shows the sublingual cavity post excision. Adequate haemostasis was achieved perioperatively however two submental drains were inserted and secured for the post-operative recovery phase.

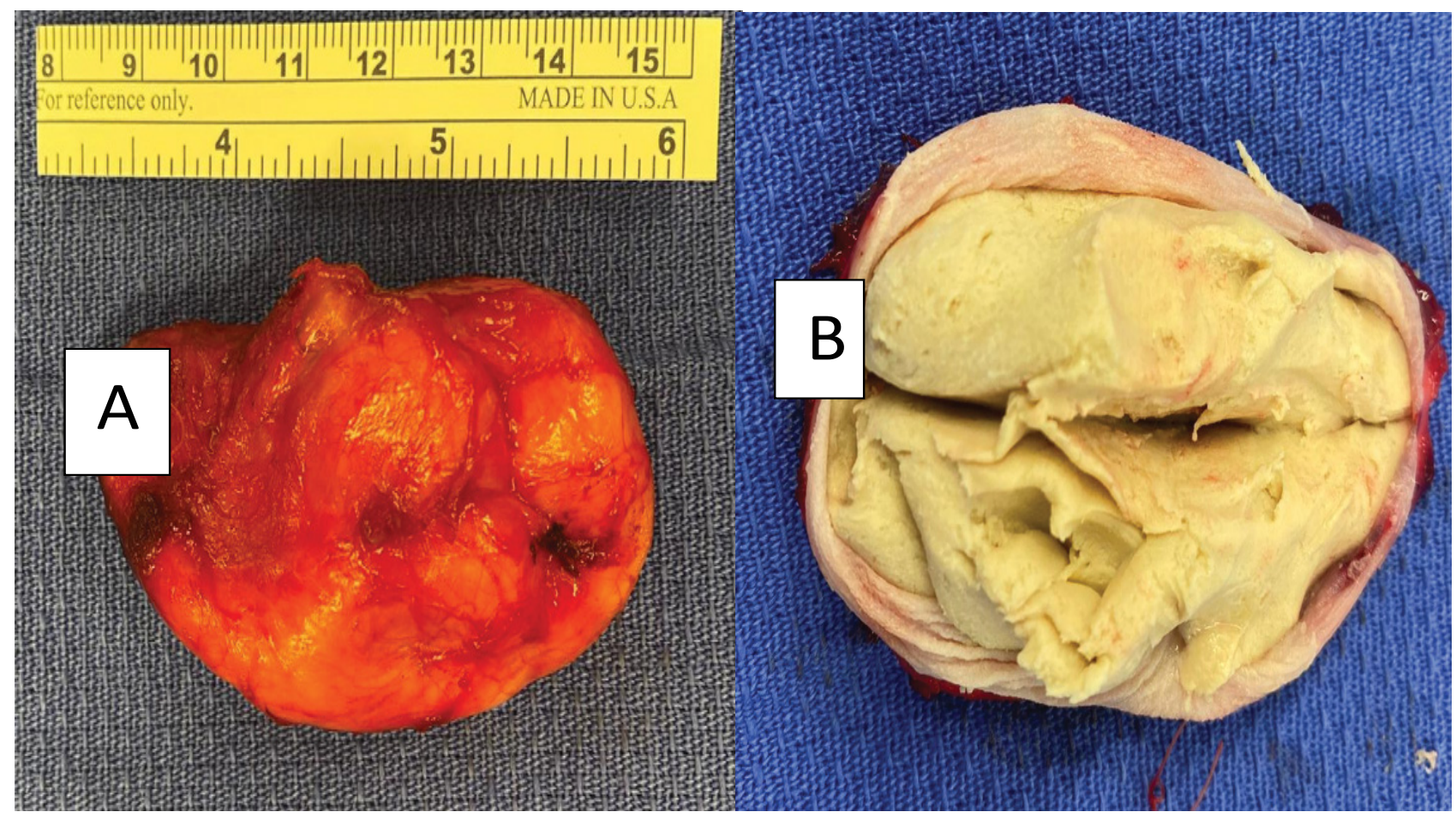

Figure 5: Highlights A) Dermoid cysts excised; B) Incision into the capsule with a lamellated layers of keratinous sebum-like content with evidence of skin derivatives. 


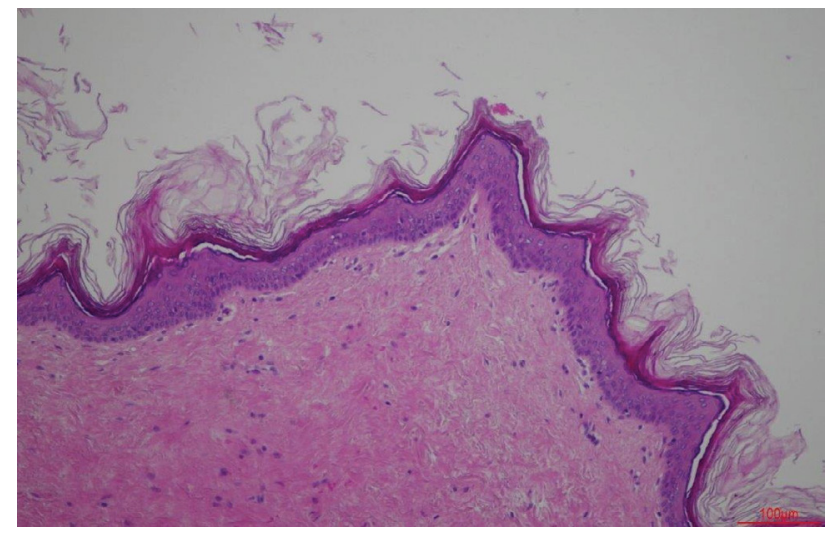

Figure 6: Photomicrograph of the dermoid cyst containing keratin and lined by orthokeratinized squamous epithelium with skin adnexal structures in the cyst wall. (Haematoxylin-Eosin stain). Photo courtesy of Dr. Mary Toner MB FRCPath, (Dept of Pathology, St. James's Hospital).

Sublingual dermoid cysts are painless, indolent swelling that can cause functional and cosmetic deficits in the floor of the mouth. The pathogenesis is not certain. Theories include developmental malformations caused by a defect in the fusion of embryonic mesenchyme [7], entrapment and proliferation of epithelial debris during midline fusion of the embryonic tongue during the third and fourth intrauterine weeks [21], traumatic implantation of epithelium [22] or displacement of normal epithelial bands, destined to differentiate, from their usual destination [22].

Meyer divided the cysts in the floor of the mouth into three separate entities based on their histological characteristics: Epidermoid, dermoid and teratoid. However, the term "dermoid" can encompass all three entities [20]. Histologically, dermoid cysts are lined by orthokeratinized stratified squamous epithelium with a prominent granular cell layer. Abundant keratin is often found within the cyst lumen. Areas of respiratory epithelium can be seen. The cyst wall is composed of fibrous connective tissue that contains one or more skin appendages such as sebaceous glands, hair follicles or sweat glands.

Anatomically, dermoid cysts are divided into three categories: Median genio-glossal (supramylohyoid), median geniohyoid (inframylohyoid) and lateral. The floor of mouth is the second most common located in the head and neck after the lateral eyebrow [23]. Our case is a large median geniohyoid dermoid cyst. Pure lateral dermoid cysts are rare, where usually multiple spaces in the floor of mouth are occupied i.e. sublingual, submental and submandibular [24]. The range of size of dermoid cysts varies in the literature from $1.2 \mathrm{~cm}$ to $12 \mathrm{~cm}$ at the greatest dimension [19]. Dimension of $6 \mathrm{~cm}$ and more have been noted as large. Size has influenced the surgical approach by means of an intra or an extraoral approach [23].

Differential diagnosis for a floor of mouth swelling can include neoplasms (lymphangioma, lipoma, hemangioma, angioma, infections odontogenic, salivary gland) and developmental processes (sublingual ranula, cystic hygroma, thy- roglossal duct cyst and ectopic thyroid tissue $[23,25,26]$.

Preoperative diagnosis is important because the treatment can vary. Most case can be clinically diagnosed by careful examination. The midline symmetrical location, dough like consistency and indentation on gentle finger pressure is a classic presentation. Plain film imaging has a poor diagnostic value. The diagnosis is predominantly made using computerized tomography, magnetic resonance imaging or ultrasonography demonstrating a cystic nature, size and anatomical location $[11,23,25]$. In a study to determine different methods of radiographic imaging, MRI was the superior method in demonstrating exact position, extension and demarcation [27]. Fine needle aspiration cytology and ultrasound with Doppler mode can also be utilized for the diagnosis [28,24].

Aspiration of the cyst contents has been advocated by Francesco 1995: However, the authors feel it is not required. Maintaining the cyst wall intact minimizes the risk of luminal contents spilling into the operative site reducing visibility. Moreover, this reduces the chance of infection and aids in countertraction.

The treatment of dermoid cysts is surgical excision. Multiple techniques have been described, which are separated into intra and extraoral techniques, depending on the size and location of the lesion [20]. For small to moderate sized lesions, an intraoral approach is advocated while an extraoral approach is advocated for large cysts or geniohyoid cysts $[1,9,29,30]$. This is due to the fear of inadequate access and the risk of recurrence. Secondly, salivary contamination and infection has been described as risk factors for intraoral incisions. The literature reports an intraoral approach predominance $(59.3 \%)$ versus $(30.5 \%)$ for an extraoral approach in the review by Vélez Cruz, et al. A mixed approach was only reported in 2 of the 58 cases described [19].

Intraorally, Brusati [29] proposed a midline glossotomy while Di Francesco [31] described a modified version with partial evacuation of the cyst. While a midline sagittal glossotomy provides good access, it also has drawbacks of increasing postoperative pain and oedema.

Additionally, it may result in a forked tongue or changes in articulation [13]. Extraorally, a transcutaneous approach has been described for lesions between or inferior to the geniohyoid. This results in a submental scar and also decreases access during the superior dissection of the capsule. A secondary intraoral incision can be used, but can result in an orocutaneous fistula. Lastly, a symphyseal mandibular osteotomy has been described for very large sublingual cysts in the dentate population [32]. The increased exposure comes at the expense of increase pain, oedema, and additional risk of damage to the dentition, and periodontal defects.

General anaesthetic is best for all case except for very small, superficial cases because it allows greater patient comfort and greater retraction and visualization. Nasotracheal intubation is indicated to keep the tube out of the surgical field. The procedure is performed with the patient in supine position.

Surgical approaches must provide appropriate access to 
the cyst for full extirpation as any residual cyst may occur. However, post-operative pain, oedema, lingual nerve sensation, size, shape, function, speech, taste, and wound healing must be taken into account. The authors disagree that only small to moderate lesions can be surgically excised from an intraoral approach [33]. As demonstrated in this case, even large cysts can be resected with an intraoral approach with good cosmetic and functional results. Cannulation of the Wharton's ducts will help to identify them. This will avoid inadvertent damage to them. Intraoral access to sublingual and even submental spaces can be achieved through an intraoral approach, thereby avoiding an osteotomy of the mandible or skin incision in the submental fold and definitely should be considered when the cyst is well defined.

\section{Conclusion}

Dermoid cysts in the oral cavity are rare. Their management has been reported in case reports and case series, which have been based on surgical expertise and experience. This case highlights important diagnostics measures, surgical planning and intra-operative techniques to manage a large sublingual dermoid cyst.

\section{References}

1. New G, Erich J (1937) Dermoid cysts of head and neck. Surg Gynecol Obs 65.

2. Zachariades N, Skoura-kafoussia C (1990) A life threatening epidermoid cyst of the floor of the mouth: Report of a case. J Oral Maxillofac Surg 48: 400-403.

3. Ege G, Akman H, Senvar A, et al. (2003) A case report: Sublingual dermoid cyst. Tani Girisim Radyol 9: 57-59.

4. Ponte F De, Brunelli A, Marchetti E, et al. (2002) Sublingual epidermoid cyst. J Craniofac Surg 13: 308-310.

5. Kandogan T, Koc M, Vardar E, et al. (2007) Sublingual epidermoid cyst: A case report. J Med Case Rep 1: 87.

6. Seah T, Sufyan W, Singh B, et al. (2004) Case report of a dermoid cyst at the floor of the mouth. Ann Acad Med Singapore 33: 7779.

7. Vargas F, Lorenzo R, FJ A, et al. (2007) Dermoid cyst of the floor of the mouth. Acta Otorinolaringol Esp 58: 31-33.

8. Black E, Leathers R, Youngblood D, et al. (1993) Dermoid cyst of the floor of the mouth. Oral Surg Oral Med Oral Pathol Oral Radiol Endod 75: 556-558.

9. Howell C (1985) The sublingual dermoid cyst: Report of five cases and review of the literature. Oral Surg Oral Med Oral Pathol Oral Radiol Endod 59: 578-580.

10. Shaari C, Ho B, Shah K, et al. (1995) Lingual dermoid cyst. Otolaryngol Head Neck Surg 112: 476-478.

11. King R, Smith B, Burk J, et al. (1994) Dermoid cyst in the floor of the mouth. Review of the literature and case reports. Oral Surg Oral Med Oral Pathol Oral Radiol Endod 78: 567-576.

12. Mosby E, Robertson G, Sugg W, et al. (1974) Compound dermoid cyst of the floor of the mouth. J Oral Surg 32: 601-603.

13. Velcek F, Klotz D, Ladogana L, et al. (1979) Tongue lesions in children. J Pediatr Surg 14: 238-246.

14. Goldberg A, Hines D (1965) Dermoid cyst of the tongue: Report of a case. J Oral Surg 23: 649.

15. Akao I, Nobukiyo S, Kobayashi T, et al. (2003) A case of large dermoid cyst in the floor of the mouth. Auris Nasus Larynx 30: S137-S139.

16. El-hakim I, Alyamani A (2008) Alternative surgical approaches for excision of dermoid cyst of the floor of mouth. Int J Oral Maxillofac Surg 37: 497-499.

17. Biglioli F, Abbati S, Bazzacchi R, et al. (2003) Cyst of the floor of the mouth causing respiratory obstruction. Report of one case. Minerva Stomatol 52: 479-483.

18. Maria G De, Califano L, Luigi C, et al. (2003) Midline (Dermoid) cysts of the floor of the mouth: Report of 16 cases and review of surgical techniques. Plast Reconstr Surg 112: 1560-1565.

19. Madeleine Edith Vélez-Cruz, José Francisco Gómez-Clavel, Carlos Juan Licéaga-Escalera, et al. (2020) Sublingual dermoid cyst in an infant: A case report and review of the literature. Clin Case Rep 8: 1403-1408.

20. Longo F, Maremonti P, Mangone G, et al. (2003) Midline (dermoid) cysts of the floor of the mouth: Report of 16 cases and review of the literature. Plast Reconstr Surg 6: 1560-1565.

21. Gleizal A, Abouchebel N, Lebreton F, et al. (2006) Dermoid cyst of the tongue: An association of dermoid cyst with bronchogenic epithelium. J Cranio-Maxillofac Surg 34: 113-116.

22. Miles L, Naidoo L, Reddy J, et al. (1997) Congenital dermoid cyst of the tongue. J Laryngol Otol 111: 1179-1182.

23. Meyer I (1955) Dermoid cysts (dermoids) of the floor of the mouth. Oral Surg Oral Med Oral Pathol Oral Radiol Endod 8: 1149-1164.

24. Marino R, Pentenero M, Familiari U, et al. (2012) Dermoid Cysts of the Floor of the Mouth: A Case Report. J Clin Case Rep 259: 60-62.

25. Ariyoshi Y, Shimahara M (2003) Magnetic resonance imaging of a submental dermoid cyst: Report of a case. J Oral Maxillofac Surg 61: 507-510.

26. Zapater K, Jimenez R, Perez V, et al. (2005) Cyst and pseudocyst lesions of the floor of the mouth with submental affectation. An Otorrinolaringol Ibero Am 32: 373-387.

27. Vogl T, Steger W, Ihrler S, et al. (1993) Cystic masses in the floor of the mouth: Value of MR imaging in planning surgery. Am J Roentgenol 161: 183-186.

28. Acree T, Abreo F, Smith BR, et al. (1999) Diagnosis of dermoid cyst of the floor of the mouth by fine-needle aspiration cytology: A Case Report. Diagnostic Cytopathology 20: 78-81.

29. Brusati R, Galioto S, Tullio A, et al. (1991) The midline sagittal glossotomy for treatment of dermoid cysts of the mouth floor. J Oral Maxillofac Surg 49: 875-878.

30. Lowry R, Tempero R, Davis L, et al. (1979) Epidermoid cyst of the floor of the mouth. J Oral Surg 37: 271-273.

31. Francesco A Di, Ancona D, Franceseo A Di, et al. (1995) Intraoral approach to large dermoid cysts of the floor of the mouth : A technical note. Int J Oral Maxillofac Surg 24: 233-235.

32. Mcgregor IA: Case Report Symphyseal mandibular osteotomy in the approach to sub ngu dermoid cyst.

33. Walstad W, Soloman J, Schow S, et al. (1998) Midline cystic lesion of the floor of the mouth. J Oral Maxillofac Surg 56: 70-74. 